\title{
BIRKENHEAD TECHNICAL COLLEGE
}

$\mathrm{T}$ HE foundation stone of the new Technical College at Birkenhead was laid on May 3, 1950, by Her Majesty the Queen, now Queen Elizabeth the Queen Mother, and the College was opened officially on January 8 last by Sir Henry Cohen, \& former student of Birkenhead schools who has reached eminence in his chosen profession of medicine.

The building is in the form of a letter $\mathrm{H}$, one limb of which is six stories high and includes the classrooms, drawing offices, library, administrative offices, and staff and student common rooms. The limb at right angles to this is termed the 'Spine Block' and is of five stories housing the electrical engineering and science laboratories and domestic craft rooms, and the top floor is devoted to the College refectory and kitchen. The other limb, parallel to the classroom block, forms the workshop block, which is a singlestory structure.

The building is steel-framed, encased in concrete with pre-cast concrete floors. It is faced with wirecut bricks with the exception of the centre of the front, which is faced with Westmorland rough-hewn slate. The building is in three sections with expansion joints. Gauges heve been fitted to show the seasonal movement. The total floor area of the College is approximately $250,000 \mathrm{sq}$. ft.

At the north end of the classroom block is the hall, which will seat approximately 1,000 and is fully equipped for theatrical purposes and can be separated from the main building for use by outside cultural organizations. There is also a gymnasium.

The College is organized in the following departments : building, commerce, domestic science, electrical engineering, mechanical engineering and science.
The building was opened for instructional purposes in September 1954, and the enrolments at the moment are more than 3,600, of whom approximately 200 are full-time, 1,100 day-relesse, and 2,300 evening students.

The various departments are offering a wide range of courses, including national certificate, higher national certificate and craft courses. Thus in the Department of Building, in addition to ordinary national certificates in building, there are City and Guilds courses in brickwork, carpentry and joinery, plumbing and ships' plumbing. The Department of Commerce provides courses for national certificates in commerce, secretarial and commercial courses, intermediate and final examination courses for the various professional institutions. Ordinary and higher national certificate courses, together with City and Guilds courses in electrical installation, telecommunications and radio servicing, are offered in the Department of Electrical Engineering. In the Department of Mechanical Engineering there are courses for ordinary national diploma in mechanical engineering for seagoing engineers, ordinary and higher national certificates in mechanical engineering with endorsement subjects, ordinary and higher national certificates in naval architecture, together with craft courses in workshop practice, motor vehicle mechanics' work, sheet and plate metal work, welding; and foundry practice. In the Department of Science there are courses for ordinary and higher national certificates in chemistry, an intensive fulltime course for, and part-time courses leading to, the examination for the associateship of the Royal Institute of Chemistry, a full-time intermediate

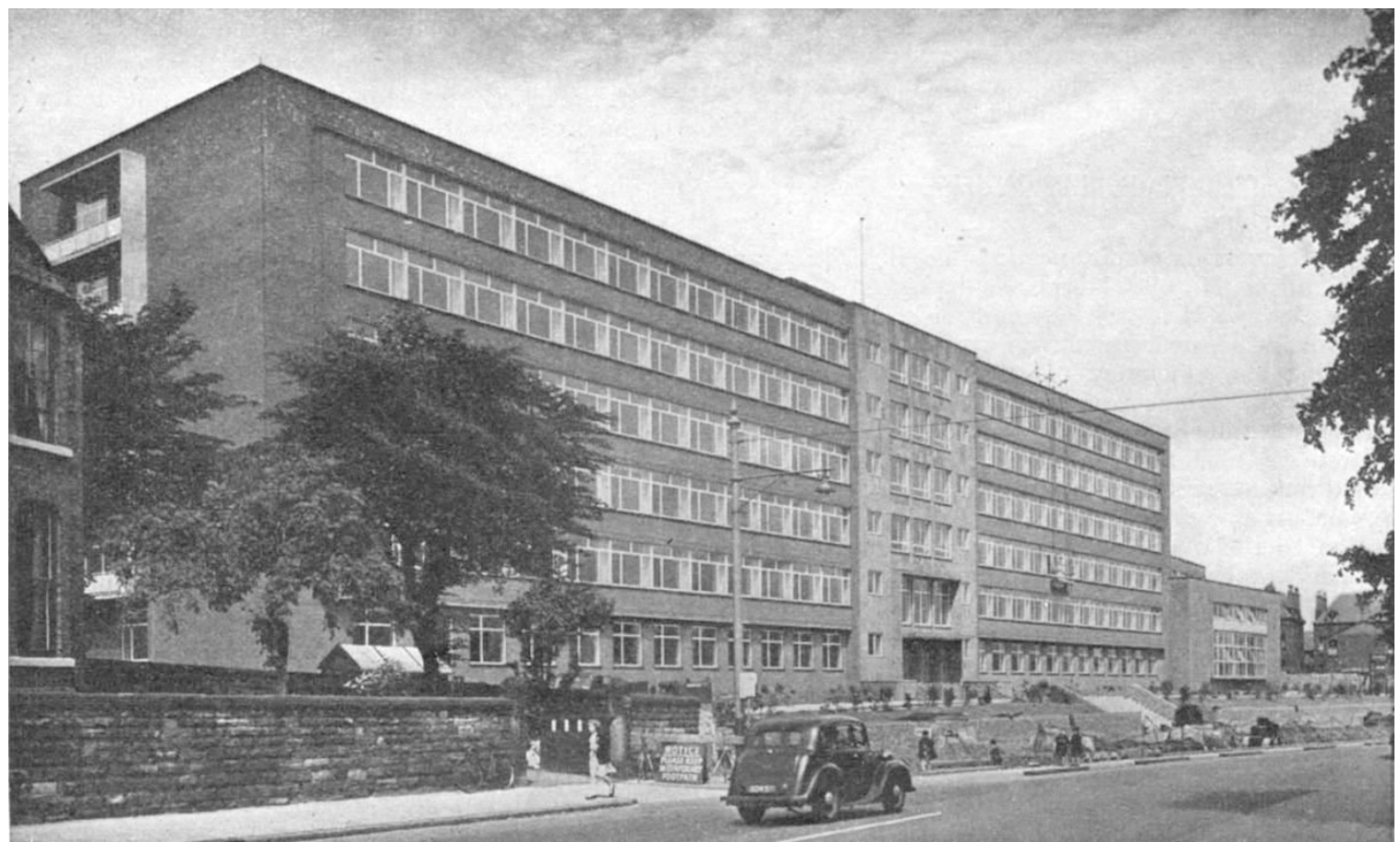

Birkenhead Technical College 
pharmacy course, and a number of short courses on glass-working, instrument technology, etc., and an ordinary national certificate course in metallurgy.

The College is also recognized for the award of the higher national certificate in chemical engineering.

The Domestic Studies Department covers a wide range of examination courses leading to the award of the City and Guilds or Union of Lancashire and Cheshire Institutes' certificates in cookery, dressmaking, needlework, tailoring, upholstery, and the Educational Development Association certificates in basketry. Bakery courses were started in September in preparation for the City and Guilds intermediate examination in bread-making and flour confectionery. Catering courses include the catering trades basic training course (City and Guilds), cookery for hotels and restaurants (City and Guilds), and catering for non-residential licensed houses.

The total accommodation in the College, apart from the administrative offices, consists of forty-two classrooms, five lecture theatres, sixteen laboratories, three commerce rooms, geography room, three domestic study rooms, three craft rooms, ten workshops, a bakery and a butchery.

The first principal of the College, Mr. C. V. Vinten Fenton, has a staff of forty-two full-time and two hundred part-time teachers. Mr. Fenton, before going to Birkenhead, was the first principal of the Peterborough College; there he was responsible for organizing technical education and saw the completion of the first phase of the new technical college built in that city.

\section{ASLIB SCOTTISH BRANCH}

\section{ANNUAL MEETING}

$\mathrm{T}$

HE annual general meeting and one-day conference of the Scottish Branch of Aslib (Association of Special Libraries and Information Bureaux) was held in the Mitchell Library, Glasgow, on February 11. The first paper of the morning was given by Dr. B. J. A. Bard, industrial manager of the National Research Development Corporation. $\mathrm{He}$ spoke of the work of the Corporation since its inception in 1950 and described its function as the development and exploitation, in the public interest, of inventions resulting from research carried out by government departments and other public bodies, and private inventions where they are of primary importance to the public interest. Dr. Bard outlined the organization of the Corporation, described how inventions are exploited and developed, and gave a general description of some of the projects in hand.

Following this paper, there was a symposium on the treatment and circulation of periodicals. The first speaker was Miss E. Handlen, librarian of the Department of the Secretary of State for Scotland. She said that, whatever the scope of a library, two demands are common to all: users want to see articles as soon as they are published, and they want to go to the library and find articles to help with a problem. Dealing with up to two thousand titles received by the Department of the Secretary of State for Scotland, these are sorted and the date of arrival recorded, and they are then circulated according to simple circulation slips made up so that the most senior officers have priority.

In this way, periodicals are circulated around seven hundred chosen users, although this figure should be trebled because officers on the lists show important articles to their juniors. All, or nearly all, periodicals are brought back to the Library, preferably before a new issue arrives. To help in this circulation, the Library has specially printed cards arranged alphabetically in a tumble-card cabinet with spaces on the face for the date entries, and other more permanent information on the back (the circulation, start of run, binding, etc.). This permits 'flagging' any item which needs special attention. One man can handle the work. It sometimes happens that a periodical circulated to medical men may contain an article of value to, say, a sanitary engineer. The supplementary service for these fits into the general circulation scheme; the first name on circulation lists is that of the librarian, and Miss Handlen includes the odd articles in the accessions lists, so that officers who have missed circulations can borrow. Such cases amount to less than ten in one month. There may be about the same number of important articles meriting inclusion in the subject card-index.

Miss Handlen favours duplication of purchase in the case of periodicals of ephemeral interest, since this permits retention of one master set and cutting of the other copies, thus saving time and labour in copying. She emphasized that circulation of periodicals is necessary where there are 700 users and 29,000 issues, and that display and retention in the library would be quite impracticable. Even in a smaller library, the display system would lead to loans, and loans are not as quick as circulations and are more costly in staff time. Full indexing of articles is not possible, and Miss Handlen said that full indexing often seems to defeat its own ends, being extremely cumbersome and costly for small results. Finally, she asked if there is not a danger of a librarian coming too much between the user and the holdings. She felt that librarianship is in danger of becoming an esoteric clerical job if too much is attempted in the way of carding every reference. Miss Handlen said that she would rather contribute $£ 25$ a year to an abstracting journal to help it become more efficient and up to date in publication than pay $£ 500$ to an extra assistant to anticipate the abstracts.

The second speaker in the symposium was $\mathbf{M r}$. A. Liddle, librarian to the firm of Babcock and Wilcox, Ltd., who described the controlled circulation of a hundred and forty periodical titles to approximately a hundred and twenty readers, most of whom are within the firm's research station. The circulation slips affixed to the periodical have columns for name, department, see pages, date sent, returned and initials. A section is provided for readers to note that they wish pages to be abstracted and indexed in the central file. Normally, periodicals are displayed for seven days so that anyone can add their name to the circulation list, or delete it if it is already there and that issue is not of further interest. Mr. Liddle thought that the time necessary for recording is justifiable by results and described the visible card system used. To help in the service of getting information to users as quickly as possible, the periodicals are first scanned and items of current interest are abstracted and produced in the form of a weekly bulletin.

The third speaker in the symposium was $\mathrm{Mr}$. J.R.K. Pirie, librarian of the Mechanical Engineering Research Laboratory, East Kilbride, of the Department of Scientific and Industrial Research. He outlined the difficulty of circulating three hundred and 